\title{
Commentary: Theoretical and Methodological Dimensions of Convergence and Divergence of Adolescent and Parent Reports about Youth Development and Family Structure and Function-A Relational Developmental Systems Perspective
}

\author{
Richard M. Lerner ${ }^{1} \cdot$ Lily S. Konowitz $^{1}$
}

Received: 25 July 2016/Accepted: 28 July 2016/Published online: 10 August 2016

(c) Springer Science+Business Media New York 2016

\begin{abstract}
Using ideas associated with relational developmental systems metatheory, we discuss the links among the operation triad model of adolescent report-parent report convergence, divergence, or compensation and the research reported in this special issue. These contributions highlight the important implications for adolescent adjustment of youth and parent reports about adolescent development and family structure and function. Relational developmental systems metatheory raises both theoretical and methodological issues for research framed by the operation triad model. These issues emphasize the specificity (non-ergodicity) of mutually influential relationships between a youth and his/her parent, that is, the specificity of the adolescent-parent relationship. Relational developmental systems -based ideas may enable the operation triad model to be a means through which the study of adolescent self-reports and parent reports will have a more central place in the construction of key features of the dynamics of adolescent-parent relationships.
\end{abstract}

Keywords Operation triad model $\cdot$ Relational developmental systems metatheory · Non-ergodicity · Idiographic methods · Parent-adolescent relationships . Process-relational paradigm

\section{Introduction}

All life comes into being through a relationship with another life (Tobach and Schneirla 1968). Among humans, the social relationship basis of development across the life

Richard M. Lerner

richard.lerner@tufts.edu

1 Institute for Applied Research in Youth Development, Tufts University, Medford, MA 02155, USA span is arguably even more fundamental, given that the features that have evolved to characterize Homo sapiensfor instance, neoteny, paedomorphy, and relative plasticity-have arisen synergistically with pair bonding, family formation, and social group interdependencies (e.g., Fisher 1982a, b; Gould 1977; Johanson and Edey 1981; Lerner 1984). In this evolution, the family has been the foundational unit within which offspring engage their social, cultural, and physical ecology and enact the transactions that comprise the socialization process (Johanson and Edey 1981; Lerner 1984).

Accordingly, the special issue of Journal of Youth and Adolescence edited by Ohannessian and De Los Reyes has brought together scholarship that pertains to the foundational component of human life: the social relationships youth have with their parents. The empirical focus of the articles in the special issue elucidates conceptual and methodological issues pertinent to understanding implications, for the positive development of youth, of the convergence and divergence of adolescents' and parents' reports about youth development and family structure and functioning. However, this research has important superordinate philosophical and theoretical implications as well. The articles implicitly, if not explicitly, reflect what is, today, the organizing metatheoretical perspective framing cutting-edge developmental science, that is, the relational developmental systems metatheory (Overton 2015; see too Lerner 2015). The articles all point to the necessity of conceptualizing development as a relational phenomenon that integrates individuals with their context and, in this special issue, particularly within their family/parental context. As such, the articles illustrate several of the key ideas associated with relational developmental systems metatheory and, as well, with the process relational paradigm from which it is derived (Overton 2015). The 
operation triad model (De Los Reyes et al. 2013), the modified version of which focused on adolescent and parent reports of family functioning discussed by De Los Reyes and Ohannessian (2016), as well as the methodological issues the operation triad model raises, can be usefully understood, and perhaps as well advanced, by discussing the links among the operation triad model, the research reported in the special issue, and the ideas associated with the relational developmental systems metatheory. It is useful, then, to summarize these ideas.

\section{The Relational Developmental Systems Metatheory}

Scientific paradigms are philosophical statements that shape scholars' concepts, assumptions, and presuppositions about the nature of the world; paradigms specify what empirical phenomena or relations are expected within the natural (or normal) world and, in turn, what phenomena or relations are either excluded or anomalous (Kuhn 1962; Overton 2015). Paradigms, in turn, provide a vocabulary for generating ideas about how scientific theories should be constructed, in order to both integrate existing observations about the world and to generate new observations (Lerner 2002; Overton 2015). These guidelines for theory construction are metatheories. In other words, a metatheory provides a conceptual framework for the generation of lower-order theories, or empirically-testable models, that, in turn, are used to integrate existing data and to lead to the generation of additional data (Lerner 2002; Overton 2013, 2015).

The relational developmental systems metatheory, used to frame several theories of human development (see Lerner 2002, Lerner et al. 2015; and Overton and Molenaar 2015, for examples), has been articulated most compellingly by Overton (e.g., 2013, 2015; Overton and Mueller 2013). The relational developmental systems metatheory is derived from a process-relational paradigm (Overton 2015). Overton explains that, compared to a Cartesian worldview, the process-relational paradigm, in understanding human development, focuses on process (systematic changes in the developmental system), becoming (moving from potential to actuality; a developmental process as having a past, present, and future; Whitehead 1929/1978), holism (the meanings of entities and events derive from the context in which they are embedded), relational analysis (assessment of the mutually influential relations within the developmental system), and the use of multiple perspectives and explanatory forms (employment of ideas from multiple theory-based models of change within and of the developmental system). Within the process-relational paradigm, the organism is seen as inherently active, self-creating (autopoietic), self-organizing, self-regulating (agentic), nonlinear and complex, and adaptive (Overton 2015; see also Sokol et al. 2015).
Derived from this paradigm, the relational developmental systems approach to theory rejects split conceptions in favor of an approach that emphasizes the study and integration of different levels of organization ranging from biology and physiology to culture and history as a means to understand life-span human development (Lerner 2006; Overton 2013, 2015). Accordingly, the conceptual emphasis in relational developmental systems -based theories is placed on mutually influential relations between individuals and contexts, represented as individual-context relations. In this special issue, these relations would be represented as adolescent-parent relationships.

Overton (2015) has explained that, in the process-relational paradigm, scientists may focus on either the role of the individual and/or the context-in the case of this special issue, on parents-in seeking to understand particular instantiations of relations between the individual and context. This changing focus in developmental analysis involves different moments, or points, within a research program. One moment involves the idea of the identity of opposites, a second moment involves the opposites of identity, and a third (relationally integrative) moment involves the synthesis of wholes.

The first moment, the identity of opposites, recognizes that both individual and context define, and are mutually constituted by, each other. In this moment in programmatic developmental inquiry, the emphasis is on the fusion or integration of the person-context relation (on the individual adolescent-parent relationship) as the primary unit of analysis for understanding development. The second moment, opposites of identity, allows one, in effect, to hold the other parts of the integrated system in abeyance, and focus on one part of the system. Overton (2013, p. 48) explains that:

Reestablishing a stable base - not an absolute fixity, nor an absolute relativity, but a relative relativity (Latour 1993) - [enables]... the law of contradiction ... [to be] reasserted and categories [to] again exclude each other. As a consequence of this exclusion, parts exhibit unique identities that differentiate each from the other.

Finally, the third moment, the synthesis of wholes, occurs when the first two moments are embedded in a multiperspective, process-relational paradigm and are recognized as mutually necessary in a systematic, integrative program of research, wherein one needs both of the first two moments.

Due to the contributions of Overton in regard to articulating the process-relational paradigm and the metatheory, and of others who have contributed to these frames for developmental science (e.g., Gottlieb 1997, 1998; and see the chapters in Overton and Molenaar 2015), the sun has 
set on Cartesian split, reductionist accounts of developmental processes, such as ones stressing nature or nurture. In contrast, relational developmental systems-based models emphasize that the basic process of human development involves mutually-influential relations between the developing individual and the multiple levels of his/her changing context, that is, on individual-context relations. The individual influences (i.e., constitutes a source of regulation) on the context, just as the context is a source of regulation on the individual. That is, these reciprocal, bidirectional relations regulate (govern) the course of development (its pace, direction, and outcomes).

As we have noted, across both their phylogeny and within their ontogeny, the individual's mutually influential links with his/her family, that is, adolescent-parent relationships, constitute the foundational instances of these relations in human development. When these bidirectional relations, these developmental regulations, are mutually beneficial to both individual and context, to both the adolescent and his/her parent in the case of the foci of the research reported in this special issue, they may be termed adaptive developmental regulations (Brandtstädter 1998).

Of course, not all instances of adolescent-parent developmental regulations are going to be adaptive over the course of the young person's relationships with his/her family. Indeed, an important contribution of the operation triad model is that it describes the exchanges between parents' and adolescents' reports of youth development and family structure and function that may be either positive or negative in valence (in regard to indicating youth adjustment or well-being) in the presence of diverging or converging operations (the authors use a third operation, compensating operations, to designate instances in which parents' and adolescents' reports diverge due to methodological factors rather than meaningful relational phenomena). Within the components of converging and diverging operations, outcomes may be positive or negative. This possibility allows for rich and complex descriptions of the importance of self- and parent-report measures of youth and family variables.

This contribution of the operation triad model underscores the substantive significance of gathering self-report and parent-report data. A criticism of such reports may be that they provide weak data at best or, even worse, fundamentally flawed information that is of little value in understanding development. The basic idea involved in such criticism may be that self reports are only perceptions that may have little resemblance to actual behaviors; such an assertion may be predicated on the view that behaviors, as compared to self reports of behaviors, constitute a sort of "gold standard" in indexing family functioning or youth behavior. However, behavioral observations are also open to a host of methodological challenges in regard to data collection, coding, and analysis. For these reasons, the operation triad model does not "pit" methods against one another. Rather, one interprets meaning from subjective reports (or lack thereof) in regard to their links to independent assessments of the phenomena measured by the subjective reports (e.g., behavioral observations, physiological indices, performance-based measures, official records). In addition, the methodological challenges of report data are addressed in the operation triad model by delineating the component of compensating operations, which is a set of conditions that allow for testing whether methodological features of adolescent and/or parent reports account for divergence in estimates of psychosocial functioning.

Moreover, one's method of choice in a study of youth and families should be a decision based on the research question one is addressing. Good science rests upon using a method that derives from, and that fits with, theory-predicated questions. In the conduct of good science, one does not fit one's questions to a particular method. As such, self reports, that is, perceptions of behavior, may be an appropriate method if one has a theory-predicated question about such phenomena. Indeed, research reported in this special issue demonstrates the usefulness of such verbal report data in illuminating the dynamics of adolescent-parent relationships. In this special issue, youth and parent perceptions have been demonstrated to be an important, and ecologically valuable, component of these relationships.

However, the operation triad model, and the research in this special issue illustrating its use, indicate that any of the three operations in the operation triad model may be associated, at a specific time in development, for specific youth and families, with either positively or negatively valenced indicators of adolescent adjustment and family function. Precisely because of these findings, it is important to move beyond the descriptive uses of the operation triad model conceptualization. A key next step is to formulate a way to use this model in explanatory research pertinent to the relational developmental systems within which adolescent-parent relations are embedded. To help move the operation triad model in this direction, it is useful to consider methodological issues raised by relational developmental systems metatheory.

De Los Reyes and Ohannessian (2016) have masterfully identified several of the methodological challenges associated with research using parent- and youth-reports of adolescent and family variables. Both the operation triad model itself, in regard to the compensating operations component, and the research reported across the special issue, are conducted with recognition of the need to take steps to address methodological problems that may arise from variation in item content or response options, lack of measurement invariance, or use of difference scores instead 
of data analytic procedures such as polynomial regression methods. ${ }^{1}$ However, relational developmental systems ideas point to several other methodological issues that need to be considered.

\section{Some Methodological Implications of the Relational Developmental System Metatheory}

De Los Reyes and Ohannessian (2016) explain that, in some cases, parent- and youth- report convergence is associated with positive indicators of adolescent or family variables; in some other cases, it is not. In turn, they also explain that, in some cases, parent- and youth-report divergence is associated with positive indicators of adolescent or family variables; in some other cases, it is not. Within their article, and in the other articles in the special issue, the bases of this variation are not elucidated. Relational developmental systems-based ideas provide some direction about how the conditions under which such variation occurs may be more precisely identified at the level of specific families and, in turn, how more nomothetic patterns of relations can subsequently be discerned. Accordingly, principles of convergence and divergence might be generated.

Such work, which would merge idiographic, differential, and nomothethic analysis (Emmerich 1968; Lerner 2002 , 2012), rests on a recognition that typical, grouporiented approaches to conceptualizing the nature of development and the analyses coupled with analyzing developmental data have been ill-conceived (Rose 2015). That is, development involves intraindividual change, and the basic unit of analysis in relational developmental systems-based empirical approaches to such change involves a focus on the mutually influential exchanges between and individual and his/her context, on individual-context relations. As such, research in relational developmental systems-based human development scholarship should be authentically person-centered, as compared to variablecentered (see von Eye et al. 2015). However, the meaning of person-centered is not commensurate with the focus on the individual in such procedures as latent class analysis, latent trajectory analysis, growth mixture modeling, or other similar procedures. The person-centered focus associated with relational developmental systems metatheory

\footnotetext{
${ }^{1} \mathrm{We}$ believe that employing polynomial regression procedures provides a useful "remedy" to many of the shortcomings of the use of difference scores in prediction research. However, we should note that these shortcomings derive from the case of the components of difference scores being positively correlated, which is generally the situation of course. In such cases, the difference score is less reliable than either component score; hence lower predictive efficacy would be expected. However, if the components of differences scores are negatively correlated, then the difference score is more reliable than either component (Baltes et al. 1977; Cronbach and Ferby 1970).
}

involves the view that developmental science is a nonergodic field (Nesselroade and Molenaar 2010; Molenaar and Nesselroade 2014, 2015; Rose 2015).

To explain, we have noted that developmental science is the study of change within the individual, within the individual-context relation, and within the autopoietic relational developmental system (Witherington 2014, 2015). Developmental scientists do not ask, therefore, whether there is change but, rather, if and how one instance of a specific change matters for another specific instance of change (Bornstein 2006, in press). However, Molenaar (2014) explained that the standard approach to statistical analysis in the social and behavioral sciences is not focused on change but, instead, derived from mathematical assumptions regarding the constancy of phenomena across people and, critically, time.

He noted that these assumptions, the ergodic theorems, lead to statistical analyses placing prime interest on the population level. Interindividual variation, and not intraindividual change, is the source of this population information (Molenaar 2014). However, within the process-relational paradigm (Overton 2015), development is nonlinear and characterized by autopoietic (self-constructing) and hence idiographic intraindividual change, features of human functioning that violate the ideas of ergodicity. Accordingly, use of the relational developmental systems metatheory as a frame for research requires a rejection of use of data analytic tools predicated on the ergodic theorems that constitute the bases of traditional statistical procedures (Molenaar and Nesselroade 2014, 2015; Nesselroade and Molenaar 2010; Rose 2015).

To illustrate, consider as a sample case Gaussian (normally distributed) processes. Molenaar (2014) noted that any ergodic Gaussian process has to obey the following two necessary conditions: (1) The Gaussian process has to be stationary, indicating that the mean of the process has to be constant in time, the variance of the process has to be constant in time, and the sequential dependencies characterizing the process only depend upon the relative distance, or lag, between time points; and (2) The Gaussian process also has to be homogeneous across individuals (indicating that each participant in the population or group has to obey the same dynamic model). Simply, the assumption used when framing statistical analysis through the use of the ergodic theorem is that the structure of interindividual variation of a developmental process at the population level is equivalent to the structure of intraindividual variation at the individual level (Molenaar 2014; Molenaar and Nesselroade 2015).

However, developmental processes have time-varying means, variances, and/or sequential dependencies, and therefore the structure of interindividual variation at the population level is not equivalent to the structure of 
intraindividual variation at the level of individual (Molenaar 2014). Developmental processes are therefore nonergodic. As a consequence, to obtain valid information about developmental processes, it is necessary to study intraindividual variation within single individuals (Molenaar and Nesselroade 2015). To enable such analyses, Nesselroade and Molenaar (2010) have developed procedures such as the idiographic filter, which involves use of the dynamic factor model at the level of the individual but then generates group-differential or nomothetic latent constructs to enable generalization across participants. Through use of procedures such as the idiographic filter, developmental scientists can capture the non-ergodic nature of intraindividual change and, as well, produce generalities about groups that apply as well to the individuals within them.

How, then, may research proceed? How can these ideas help to better elucidate the bases of the adolescent-parent relationship that result in convergence or divergence in parents' and adolescents' reports? Consistent with the Bornstein (2006, in press) "specificity principle," we suggest that addressing a multipart "what" question is the key to conducting programmatic research about the function, structure, and content of development across the life span. To test relational developmental systems-based ideas about the ontogenetically changing structure of development across the life span-to test empirically the processrelational conception of intraindividual change (Overton 2015; Sokol et al. 2010, 2015) — the task for developmental researchers is to undertake programs of research to ascertain answers to following multipart "what" question. In a general form this questions asks:

1. What structure-content relations emerge; that are linked to

2. What antecedent and consequent developmental regulations (to what trajectory of individual-context relations); at

3. What points in development; for

4. What individuals; living in

5. What contexts; across

6. What historical periods; and

7. For what indicators of positive or problematic development?

In turn, in regard to the convergence or divergence between youth and parent reports, this question may be posed as:

1. What relations between the report of an adolescent and the report of his/her parent emerge; that are linked to

2. What antecedent and consequent developmental regulations (to what trajectory of individual-context relations); at
3. What points in development; for

4. What individuals; living in

5. What contexts; across

6. What historical periods; and

7. For what indicators of positive or problematic development?

How may answers to such a complex question lead to either nomothetic statements or, perhaps ideally, to the specification of principles of generality beyond specific instances on adolescent-parent relations? To illustrate how this question may be addressed, Molenaar and Nesselroade (2014, 2015) offer one possible answer. As we have noted, they describe how the integration of the dynamic factor model and the idiographic filter provides a promising way to first ascertain what individuals have in common and then build generalizations on that information. This approach stands in marked contrast to initially aggregating the individual-level information and extracting generality from it in the form of average tendencies - the approach of traditional differential psychology.

The answer presented by Molenaar and Nesselroade (2014, 2015) is an example of the application of systems science methods to developmental science framed by relational developmental systems-based theories (see also Molenaar et al. 2014). The dynamic factor analysis is an example of a state space model, in that it integrates a model of the dynamic evolution of the state process and another model linking the state process at each time point to the observed process at that time. Accordingly, systems science methods may provide other ways to address the questions that comprise the specificity principle of Bornstein (2006, in press). Such methods may address complex changes in nonlinear relationships, bidirectional relationships, time-delayed effects, and emergent properties of the relational development system (Mabry and Kaplan 2013). Examples of systems science methods are computational/mathematical modeling and simulation, micro-simulation, agent-based modeling, system dynamics modeling, network analysis, and discrete event simulation (Urban et al. 2011).

In sum, there are a burgeoning set of methodological tools that can assist developmental scientists in the nonergodic assessment of the specific conditions under which adolescents' reports and parents' reports converge or diverge. These tools have the potential to enable developmental scientists to build on the excellent work represented in the Ohannessian and De Los Reyes special issue and construct a theoretical edifice around the ideas found in the operation triad model (De Los Reyes and Ohannessian 2016), one that elevates the study of adolescent self-reports and parent reports about their adolescent to a more central place in the construction of a fuller understanding of key 
features of the dynamics of the adolescent-parent relationship.

\section{Conclusions}

The relational developmental systems metatheory that has crystallized today is now regarded as the fundamental frame in developmental science for theory-predicated research and associated methodological innovations, and for enacting applications aimed at optimizing human development (e.g., Bornstein and Leventhal 2015; Damon 2015; Lamb 2015; Lerner 2015; Liben and Müller 2015; Molenaar et al. 2014; Overton and Molenaar 2015). However, to fully capitalize on these attributes of RDSbased scholarship, scholars such as those represented in this special issue (De Los Reyes and Ohannessian 2016) may find it useful to make additions to the tools of research now current in the literature integrating youth and parent reports of adolescent development and family structure and function. We believe that such expansion of the methodological features of this literature will have a useful payoff for both science and for the youth and families of interest to scholars studying adolescent behavior and development.

One of the attractions of the relational developmental systems-based approach to human development is the aspiration to produce scholarship that matters in the real world; often, this aspiration is coupled with the desire to address the need for evidence-based means to reduce or, ideally, eliminate the challenges to healthy, positive development facing diverse children and families. We believe that fuller embeddedness of operation triad modelbased research within the conceptual and methodological approaches advanced within the relational developmental systems metatheory can better describe, explain, and optimize the outcomes of convergence and divergence between youth and parent reports of adolescent and family variables. Such work can advance both understanding of the dynamics of the relational developmental system within which youth develop and, as well, advance the power of the operation triad model in promoting thriving among diverse children and families.

Acknowledgments We thank Sara K. Johnson, Michelle B. Weiner, and Jacqueline V. Lerner for their comments.

Funding This article was supported in part by Grants from the John Templeton Foundation and the Templeton Religion Trust.

Author Contributions RML and LSK co-wrote this article. Both of the authors read and approved the final manuscript.

Conflict of interest The authors report no conflict of interests.

\section{References}

Baltes, P. B., Reese, H. W., \& Nesselroade, J. R. (1977). Life-span developmental psychology: Introduction to research methods. Monterey, CA: Brooks/Cole.

Bornstein, M. H. (2006). Parenting science and practice. In K. A. Renninger \& I. E. Sigel (Eds.), Handbook of child psychology. Vol. 4: Child psychology in practice (6th ed., pp. 893-949). Editors-in-chief: W. Damon \& R. M. Lerner. Hoboken, NJ: Wiley.

Bornstein, M. H. (in press). The specificity principle in acculturation science. Perspectives on Psychological Science.

Bornstein, M. H., \& Leventhal. T. (Eds.). (2015). Handbook of child psychology and developmental science, Volume 4: Ecological settings and processes in developmental systems (7th ed.). Editor-in-chief: R. M. Lerner. Hoboken, NJ: Wiley.

Brandtstädter, J. (1998). Action perspectives on human development. In R. M. Lerner (Ed.), Theoretical models of human development. Vol. 1: The Handbook of child psychology (5th ed., pp. 807-863), Editor-in-chief: W. Damon. New York: Wiley.

Cronbach, L. J., \& Furby, L. (1970). How we should measure "change": Or should we? Psychological Bulletin, 74(1), 68-80.

Damon, W. (2015). Foreword. In Handbook of child psychology and developmental science (7th ed.). Editor-in-chief: R. M. Lerner (pp. vii-xiii). Hoboken, NJ.: Wiley.

De Los Reyes, A., \& Ohannessian, C. M. (2016). Introduction to the special issue: Discrepancies in adolescent-parent perceptions of the family and adolescent adjustment. Journal of Youth and Adolescence. doi:10.1007/s10964-016-0533-z.

De Los Reyes, A., Thomas, S. A., Goodman, K. L., \& Kundey, S. M. A. (2013). Principles underlying the use of multiple informants' reports. Annual Review of Clinical Psychology, 9, 123-149. doi:10.1146/annurev-clinpsy-050212-185617.

Emmerich, W. (1968). Personality development and concepts of structure. Child Development, 39, 671-690.

Fisher, H. E. (1982a). Of human bonding. The Sciences, 22(18-23), 31.

Fisher, H. E. (1982b). Is it sex? Helen E. Fisher replies. The Sciences, $22,2-3$.

Gottlieb, G. (1997). Synthesizing nature-nurture: Prenatal roots of instinctive behavior. Mahwah, $\mathrm{NJ}$ : Lawrence Erlbaum Associates.

Gottlieb, G. (1998). Normally occurring environmental and behavioral influences on gene activity: From central dogma to probabilistic epigenesis. Psychological Review, 105, 792-802.

Gould, S. J. (1977). Ontogeny and phylogeny. Cambridge, MA: Harvard University Press.

Johanson, D. C., \& Edey, M. A. (1981). Lucy: The beginnings of humankind. New York: Simon \& Schuster.

Kuhn, T. S. (1962). The structure of scientific revolutions. Chicago: University of Chicago Press.

Lamb, M. E. (Ed.). (2015). Handbook of child psychology and developmental science, Volume 3: Social, emotional, and personality development ( 7 th ed.). Editor-in-chief: $\mathrm{R}$. M. Lerner. Hoboken, NJ: Wiley.

Latour, B. (1993). We have never been modern. Cambridge, MA: Harvard University Press.

Lerner, R. M. (1984). On the nature of human plasticity. New York: Cambridge University Press.

Lerner, R. M. (2002). Concepts and theories of human development (3rd ed.). Mahwah, NJ: Lawrence Erlbaum.

Lerner, R. M. (2006). Developmental science, developmental systems, and contemporary theories of human development. In R. M. Lerner (Ed.), Theoretical models of human development. Vol. 
1: The handbook of child psychology (6th ed., pp. 1-17). Editorsin-chief: W. Damon \& R. M. Lerner. Hoboken, NJ: Wiley.

Lerner, R. M. (2012). Essay review: Developmental science. Past, present, and future. International Journal of Developmental Science, 6(1-2), 29-36.

Lerner, R. M. (2015). Preface. In Handbook of child psychology and developmental Science (7th ed.). Editor-in-chief: R. M. Lerner (pp. xv-xxi). Hoboken, NJ: Wiley.

Lerner, R. M., Hershberg, R., Hilliard, L., \& Johnson, S. K. (2015). Concepts and theories of human development: Historical and contemporary dimensions. In M. H. Bornstein \& M. E. Lamb (Eds.), Developmental science: An advanced textbook (7th ed., pp. 3-41). New York: Psychology Press.

Liben, L. S., \& Müller, U. (Eds.). (2015). Handbook of child psychology and developmental science, Volume 2: Cognitive processes (7th ed.). Editor-in-chief: R. M. Lerner. Hoboken, NJ: Wiley.

Mabry, P. L., \& Kaplan, R. M. (2013). Systems science: A good investment for the public's health. Health Education and Behavior, 40(1 suppl), 9S-12S.

Molenaar, P. C. (2014). Dynamic models of biological pattern formation have surprising implications for understanding the epigenetics of development. Research in Human Development, $11(1), 50-62$.

Molenaar, P. C. M., Lerner, R. M., \& Newell, K. (Eds.). (2014). Handbook of developmental systems theory and methodology. New York: Guilford.

Molenaar, P. C., \& Nesselroade, J. R. (2014). New trends in the inductive use of relation developmental systems theory: Ergodicity, nonstationarity, and heterogeneity. In P. C. Molenaar, R. M. Lerner, \& K. M. Newell (Eds.), Handbook of developmental systems and methodology (pp. 442-462). New York: Guilford.

Molenaar, P. C. M., \& Nesselroade, J. R. (2015). Systems methods for developmental research. In W. F. Overton \& P. C. Molenaar (Eds.), Theory and method. Volume 1 of the Handbook of child psychology and developmental science (7th ed., pp. 652-682). Editor-in-chief: R. M. Lerner. Hoboken, NJ: Wiley.

Nesselroade, J. R., \& Molenaar, P. C. M. (2010). Emphasizing intraindividual variability in the study of development over the life span. In W. F. Overton (Ed.), The handbook of life-span development. Vol. 1: Cognition, biology, methods (pp. 30-54). Editor-in-chief: R. M. Lerner. Hoboken: Wiley.

Overton, W. F. (2013). Relationism and relational developmental systems: A paradigm for developmental science in the postCartesian era. In R. M. Lerner and J. B. Benson (Eds.), Advances in Child Development and Behavior. Volume 44: Embodiment and epigenesis: Theoretical and methodological issues in understanding the role of biology within the Relational Developmental System, Part A: Philosophical, theoretical, and biological Dimensions. (pp. 24-64). Waltham, MA: Elsevier.

Overton, W. F. (2015). Process and relational developmental systems. In W. F. Overton \& P. C. Molenaar (Eds.), Theory and method. Volume 1 of the Handbook of child psychology and developmental science (7th ed., pp. 9-62). Editor-in-chief: R. M. Lerner. Hoboken, NJ: Wiley.

Overton, W.F., \& Molenaar, P. C. (Eds.). (2015). Handbook of child psychology and developmental science, Volume 1: Theory and method (7th ed.). Editor-in-chief: R. M. Lerner. Hoboken, NJ: Wiley.

Overton, W. F., \& Mueller, U. (2013). Metatheories, theories, and concepts in the study of development. In R. M. Lerner, M A. Easterbrooks, \& J. Mistry (Eds.), Handbook of psychology, Volume 6: Developmental psychology (2nd ed.). (pp. 19-58). Editor-in-Chief: Irving B. Weiner. Hoboken, NJ: Wiley.

Rose, T. (2015). The end of average. New York: Harper One.

Sokol, B. W., Hammond, S. I., \& Berkowitz, M. W. (2010). The developmental contours of character. In T. Lovat, R. Toomey, \& $\mathrm{N}$. Clement (Eds.), International research handbook on values education and student wellbeing (pp. 579-603). Dordrecht, Netherlands: Springer.

Sokol, B. W., Hammond, S., Kuebli, J., \& Sweetman, L. (2015). The development of agency. In W. F. Overton \& P. C. Molenaar (Eds.), Theory and method. Volume 1 of the Handbook of child psychology and developmental science (7th ed., pp. 284-322). Editor-in-chief: R. M. Lerner. Hoboken, NJ: Wiley.

Tobach, E., \& Schneirla, T. C. (1968). The biopsychology of social behavior of animals. In R. E. Cooke \& S. Levin (Eds.), Biologic basis of pediatric practice (pp. 68-82). New York: McGrawHill.

Urban, J. B., Osgood, N., \& Mabry, P. (2011). Developmental systems science: Exploring the application of non-linear methods to developmental science questions. Research in Human Development, 8, 1-25.

von Eye, A., Bergman, L. R., Hsieh, C. (2015). Person-oriented methodological approaches. In W. F. Overton \& P. C. Molenaar (Eds.), Theory and method. Volume 1 of the Handbook of child psychology and developmental science (7th ed., pp. 789-841). Editor-in-chief: R. M. Lerner. Hoboken, NJ: Wiley.

Whitehead, A. N. (1929/1978). Process and reality: Corrected edition. New York: The Free Press.

Witherington, D. C. (2014). Self-organization and explanatory pluralism: Avoiding the snares of reductionism in developmental science. Research in Human Development, 11(1), 22-36.

Witherington, D. C. (2015). Dynamic systems in developmental science. In W. F. Overton \& P. C. Molenaar (Eds.), Theory and method. Volume 1 of the Handbook of child psychology and developmental science (7th ed., pp. 63-112). Editor-in-chief: R. M. Lerner. Hoboken, NJ: Wiley.

Richard M. Lerner is the Bergstrom Chair in Applied Developmental Science and the Director of the Institute for Applied Research in Youth Development at Tufts University. He received his Ph.D. in developmental psychology from the City University of New York. His work integrates the study of public policies and community-based programs with the promotion of positive youth development and youth contributions to civil society.

Lily S. Konowitz is a Research Coordinator at the Institute for Applied Research in Youth Development at Tufts University. She received her B.A. from Bucknell University in May 2015. Her research interests include studying how various mentoring relationships can promote positive youth development. 